\title{
RESEARCH
}

Open Access

\section{Prevalence of drug use, alcohol consumption, cigarette smoking and measure of socioeconomic-related inequalities of drug use among Iranian people: findings from a national survey}

Mehdi Moradinazar ${ }^{1}$, Farid Najafi ${ }^{1}$, Farzad Jalilian², Yahya Pasdar', Behrooz Hamzeh', Ebraim Shakiba², Mohammad Hajizadeh ${ }^{3}$, Ali Akbar Haghdoost ${ }^{4}$, Reza Malekzadeh ${ }^{5}$, Hossein Poustchi ${ }^{6}$, Marzeyeh Nasiri ${ }^{7}$, Hassan Okati-Aliabad ${ }^{8}$, Majid Saeedii ${ }^{9}$, Fariborz Mansour-Ghanaei ${ }^{10}$, Sara Farhang ${ }^{11}$, Ali Reza Safarpour ${ }^{12}$, Najmeh Maharlouei ${ }^{13}$, Mojtaba Farjam ${ }^{14}$, Saeed Amini ${ }^{15}$, Mahin Amini ${ }^{1}$, Ali Mohammadi ${ }^{1}$ and Mehdi Mirzaei-Alavijeh ${ }^{2^{*}}$

\begin{abstract}
Background: Drug use can lead to several psychological, medical and social complications. The current study aimed to measure and decomposes socioeconomic-related inequalities in drug use among adults in Iran.

Methods: This was a cross-sectional study The PERSIAN Cohort is the largest and most important cohort among 18 distinct areas of Iran. This study was conducted on 130,570 adults 35 years and older. A structured questionnaire was applied to collect data. The concentration index (C) was used to quantify and decompose socioeconomic inequalities in drug use.

Results: The prevalence experience of drug use was $11.9 \%$. The estimated $C$ for drug use was -0.021 . The corresponding value of the $C$ for women and men were -0.171 and -0.134 , respectively. The negative values of the $C$ suggest that drug use is more concentrated among the population with low socioeconomic status in Iran $(p<0.001)$. For women, socioeconomic status (SES) $(26.37 \%)$, province residence $(-22.38 \%)$ and age $(9.76 \%)$ had the most significant contribution to socioeconomic inequality in drug use, respectively. For men, SES (80.04\%), smoking (32.04\%) and alcohol consumption (-12.37\%) were the main contributors to socioeconomic inequality in drug use.

Conclusions: Our study indicated that drug use prevention programs in Iran should focus on socioeconomically disadvantaged population. Our finding could be useful for health policy maker to design and implement effective preventative programs to protect Iranian population against the drug use.
\end{abstract}

Keywords: Inequalities, Drug use, Socioeconomic status, Concentration index, Iran

\footnotetext{
* Correspondence: mehdimirzaiea@yahoo.com

${ }^{2}$ Social Development and Health Promotion Research Center, Health Institute, Kermanshah University of Medical Sciences, Kermanshah, Iran

Full list of author information is available at the end of the article
}

(c) The Author(s). 2020 Open Access This article is licensed under a Creative Commons Attribution 4.0 International License, which permits use, sharing, adaptation, distribution and reproduction in any medium or format, as long as you give appropriate credit to the original author(s) and the source, provide a link to the Creative Commons licence, and indicate if changes were made. The images or other third party material in this article are included in the article's Creative Commons licence, unless indicated otherwise in a credit line to the material. If material is not included in the article's Creative Commons licence and your intended use is not permitted by statutory regulation or exceeds the permitted use, you will need to obtain permission directly from the copyright holder. To view a copy of this licence, visit http://creativecommons.org/licenses/by/4.0/ The Creative Commons Public Domain Dedication waiver (http://creativecommons.org/publicdomain/zero/1.0/) applies to the data made available in this article, unless otherwise stated in a credit line to the data. 


\section{Background}

Drug use (refers to any scope of use of illegal drugs: heroin, amphetamines, barbiturates, cannabis, cocaine, hallucinogens, and opioids) is one of the major health, psychosocial and socioeconomic problems in the world, and can lead to several problems and complications for addicts, their families and society $[1,2]$. There exists sex differences in the drug use in the communities; the rate of drug use in men has been significantly higher than women even though this sex gap has been steadily decreasing [3].

Iran is one of the countries where drug use prevalence has increased in recent years; this is due to various reasons such as shares border with Afghanistan in the Eastern of Iran which is the largest producer country of opium in the world, and a major route for substance transport to Europe [4]. Based on the World Health Organization (WHO), Iran has the highest rate of opium abusers in the world, and opium use in Iran is three times the global average [5]. The statistics show that there are about 2 million people use illicit drugs at a daily basis in Iran, which is about $2.7 \%$ of the population [6].

Providing knowledge about the determinants influencing drug use in the society can enable health policymakers to the development and the implementation evidence-based preemptive programs [7]. In the area of addiction tendency, various hypotheses have been expressed that none of them alone can explain this problem [8,9]. Several studies have indicated the predictive nature of socioeconomic status (SES) against drug use such as alcohol consumption, opium, cigarette smoking, and cannabis; however, the association between SES and drug use is complex [10-14]. For example, the prevalence of cigarette smoking is higher among groups with low SES and they maybe more exposure to harms related cigarette smoking [10]. A higher addiction rate also found among individuals with low SES [12]. Contrary to these results, some studies [11] reported higher alcohol consumption and cannabis use among high SES.

Although studies have been conducted on the relationship between SES and drug use in Iran, these studies have used a small sample size with a focus on only one sex (especially men) [15-17]. Thus, more studies are required to predict socioeconomic-related inequalities in drug use among adults in Iran. Given the widespread incongruities among the findings of researches, our study focused on socioeconomicrelated inequality to the drug use in among Iranian adult's population using a large sample size obtained from the Prospective Epidemiologic Research Study (PERSIAN Cohort).

\section{Methods}

Study setting

The PERSIAN Cohort is the largest and most important cohort among 18 distinct areas of Iran. This study launched nationwide by the Ministry of Health and Medical Education (MoHME) in Iran to provide information about Non-communicable Diseases (NCDs) among Iranian adults (aged 35 and above). The PERSIAN Cohort Study is a prospective study with purpose to include 180,000 Iranians aged 3570 years from 18 geographically distinct areas of Iran. While the MoHME oversees the project, researchers at local Iranian medical universities carry it out. The cohort has started in 2014 and collects information between 5000 and 10,000 people from all Iranian ethnic groups in each district area. The financial support for the study is provided by the MoHME, and the deputy of research in the medical universities in the 18 distinct areas of Iran. The protocol of PERSIAN Cohort study (including: objectives, outcomes of interest, design of study, site selection, participant selection, sample size, sampling methods, inclusion criteria, and quality assurance and quality control was published in American Journal of Epidemiology [18] and Archives of Iranian Medicine [19]. The Iranian people comprise individuals of many ethnicities. Appendix 1 shows the characteristics of cohort sites in Iran.

\section{Study tools}

The cohort questionnaire is administered by trained interviewers.

\section{Physical activity}

Physical activity was measured weekly based on all the physical activity related to exercise, work, and recreation in the past $24 \mathrm{~h}$. Physical activity questionnaire includes 19 light, moderate, and severe activities. MET is the amount of oxygen consumed at

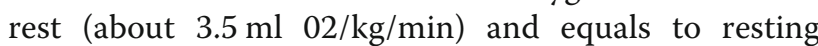
metabolic rate. Physical activity levels were classified as low (24-36.5 MET-hours per week), moderate (MET-36.6-44.9h per week) and heavy (MET- $\geq 45 \mathrm{~h}$ per week) [18].

\section{Drug use variable}

To assess whether or not the subjects had a history of drug use (included: heroin, amphetamines, barbiturates, cannabis, cocaine, hallucinogens, and Opioids), a question was asked: "Have you used illicit drug more than one time during a lifetime?" The reply options for each drug question was "Yes" or "No". 


\section{Cigarettes smoking}

Smoking status evaluated based the one National Health Interview Survey (NHIS). If respondents smoked $\geq 100$ cigarettes in their lifetime, they were defined as smokers. The ex-smoker refers to an individual who has given up a cigarette smoking. Former smokers were previous smokers but are no longer smoking [20].

\section{Water pipe smoking}

To assess whether or not the participants had experienced water pipe smoking, we used one questions "Have you ever water pipe smoking at during a lifetime?" which the response category was yes or no.

\section{Alcohol consumption}

To assess whether or not the respondents had a history of alcohol consumption a question was asked: "Have you consumed alcoholic drinks more than one time during a lifetime?" The reply options for alcohol consumption question was "Yes" or "No".

\section{Socioeconomic status index}

A principal component analysis (PCA) method was used to construct an SES index of respondents in the Cohort study. Available information on, infrastructure facilities (source of drinking water, sanitation facility), housing condition (e.g. the number of rooms, type of home ownership) and ownership of a range of durable assets (e.g. dishwasher, car, television), and education level in the dataset was used in the construction of SES variable for each participants. Participants of the study categorized into five SES quintiles, from the lowest (1st quintile) to the highest (5th quintile) SES groups.

\section{Measuring socioeconomic-related inequality in drug use}

Socioeconomic-related inequality in drug use was estimated using the Concentration index (C) approach and the Concentration curve [19]. The concentration curve is a two-dimensional graph. The horizontal axis shows the cumulative percentage of the population ranked from the poorest to the richest, and the vertical axis indicates the cumulative percentage of the health variable (in the present study: drug use). The 45-degree line represents full equality in the distribution of drug use. If the drug abuse rate is higher among socioeconomically disadvantaged individuals, the concentration curve places above the equality line. The $\mathrm{C}$ is extracted from the Concentration curve and equals twice the space between the Concentration curve and the equality line (45-degree). If the index is zero, this means that the variable is distributed equally among SES groups. The following formula was used to measured inequality and estimated the $\mathrm{C}$ (equation (1):

$$
\mathrm{C}=\frac{2 * \operatorname{cov}\left(y_{i} r_{i}\right)}{\mu}
$$

Where $y_{i}$ is health variable for the person $i, \mu$ it's mean of the health outcome variable and $r_{i}$ the fractional rank. Considering that the drug use in our study was a binary variable, the minimum and maximum values of the $C$ does range between -1 and +1 . Thus, the $C$ was normalized by dividing the estimated value of the concentration index by $1-\mu$ (equation (2) [20].

$$
C_{n}=\frac{C_{I}}{1-\mu}
$$

To determine the contribution of each factor to socioeconomic inequality in drug use, we decompose the estimated $C_{n}$ (equation (3) [21]. If we have a regression model relating a set of demographic (age, sex, marital status), behavioural (cigarette smoking, water pipe smoking) and socioeconomic variables, $x_{k}$, to the drug use status of individuals such as:

$$
y=\alpha+\sum_{k} \beta_{k} x_{k}+\varepsilon
$$

where $\beta_{k}$ are marginal effects obtained from the logistic regression. The $C_{n}$ for drug use can be decomposed as:

$$
C_{n}=\frac{\sum_{K}\left(\frac{\beta_{K} \bar{X}_{K}}{\mu}\right) C_{K}}{1-\mu}+\frac{\frac{G C_{\varepsilon}}{\mu}}{1-\mu}
$$

Where $\bar{x}_{k}$ is mean of each of the independent variables, $C_{k}$ is the concentration index for the explanatory variable $x_{k}$, and $G C_{\varepsilon}$ is the generalized $C$ for $\varepsilon$. The first part of equation ((4) indicates the contribution of each explanatory factors to the overall $C_{n}$. Based on equation (4, the $C_{n}$ can be decomposed into two components. The first component, $\sum_{k}\left(\frac{\beta_{k} \bar{x}_{k}}{\mu}\right) C_{k} / 1-\mu$, indicated how the $C_{n}$ is explained by the relationship between the independent variable and explanatory variables and the systematic changes of independent variables in the distribution of socioeconomic groups. The negative (positive) contribution of independent variable to the $C_{n}$ indicated that the distribution of independent variables across SES and the relationship of this variable to drug use are likely to contribute to the higher (lower) concentration of drug use among the poor. The second component or $G C_{\varepsilon} / \mu / 1-\mu$ indicated the inequality that is not explained by independent variables included in the model. Multivariable logistic regressions were then used to examine adjusted odds ratios (OR). 


\section{Ethical statement}

While each cohort center received the ethical approval from local universities, for the purpose of this study and pooling all PERSIAN data, the ethics committee of Kermanshah University of Medical Sciences approved the study (IR.KUMS.REC.1397.187).

\section{Results}

The mean age of participants was 49.7 years [SD: 9.2]. Approximately $55.5 \%$ of the participants were women. 90.9 and $20.2 \%$ of participants were married, and illiterate, respectively. In addition, $14 \%$ of the participants in PERSIAN cohort were a current smoker. 11.9\%
(24.1\% among men versus $2.2 \%$ among women) of the population had a history of drug use.

Table 1 reported the prevalence of drug use among adults in Iran by the respondents' characteristics in the PERSIAN cohort. As the prevalence of drug use linearly increased by age in women but did not change significantly in men $(P=0.7)$. The highest prevalence of drug use was in married people. The prevalence of drug use was decreased by education level.

Figure 1 shows sex difference in the prevalence of drug use in different provinces of Iran. As shown in the figure, the prevalence of drug use among men was found to be higher in Kerman (KE), Yazd (YA), Kohgiluyeh

Table 1 Distribution of the demographic characteristics among the participants and the prevalence of drug use in Iran by the respondents' characteristics in the PERSIAN cohort

\begin{tabular}{|c|c|c|c|c|c|}
\hline Variables & & $N(\%)$ & $\begin{array}{l}\text { Total } \\
\text { prevalence }\end{array}$ & $\begin{array}{l}\text { Male } \\
\text { prevalence }\end{array}$ & $\begin{array}{l}\text { Female } \\
\text { prevalence }\end{array}$ \\
\hline Total & & $130,570(100)$ & $11.9(15600)$ & 24.1 (13998) & $2.2(1602)$ \\
\hline \multirow[t]{7}{*}{ Age group } & $35-40$ & $27,005(20.7)$ & 9.3 & 20.6 & 1.1 \\
\hline & $41-45$ & $24,212(24.2)$ & 11.7 & 25.0 & 1.5 \\
\hline & $46-50$ & $22,645(22.6)$ & 12.5 & 26.2 & 1.8 \\
\hline & $51-55$ & $20,297(15.5)$ & 12.8 & 25.2 & 2.7 \\
\hline & $55-60$ & $17,570(13.5)$ & 13.5 & 25.3 & 3.4 \\
\hline & $61-65$ & $12,271(9.4)$ & 13.1 & 23.7 & 3.8 \\
\hline & $>66$ & $6570(5.0)$ & 12.4 & 21.1 & 4.2 \\
\hline \multirow[t]{3}{*}{ Marital status } & Married & $118,769(91.0)$ & 12.6 & 23.9 & 2.0 \\
\hline & Single & $2895(2.2)$ & 6.1 & 27.4 & 0.4 \\
\hline & Divorced/widowed & $8906(6.8)$ & 5.7 & 34.3 & 4.1 \\
\hline \multirow[t]{5}{*}{ Years of education } & Illiterate (0 year) & $26,666(20.2)$ & 8.3 & 23.6 & 3.2 \\
\hline & $1-5$ years & $41,975(31.9)$ & 11.2 & 26.7 & 2.3 \\
\hline & $6-9$ years & $23,938(18.2)$ & 17.9 & 30.3 & 2.0 \\
\hline & $10-12$ years & $22,552(17.1)$ & 14.4 & 24.2 & 1.2 \\
\hline & $>=13$ years & $16,659(12.6)$ & 7.6 & 12.0 & 0.6 \\
\hline \multirow[t]{3}{*}{ Cigarette smoking } & Never smoker & $102,141(78.2)$ & 4.5 & 10.0 & 2.0 \\
\hline & Current smoker & $18,331(14.0)$ & 43.3 & 44.9 & 12.2 \\
\hline & Former smoker & $10,097(7.8)$ & 30.6 & 33.1 & 7.7 \\
\hline \multirow[t]{2}{*}{ Alcohol consumption } & No & $118,772(91.0)$ & 8.4 & 17.9 & 2.2 \\
\hline & Yes & $11,795(9.0)$ & 47.7 & 48.8 & 11.9 \\
\hline \multirow[t]{2}{*}{ Water pipe smoking } & No & $115,979(88.8)$ & 9.2 & 20.2 & 1.7 \\
\hline & Yes & $14,581(11.2)$ & 34.0 & 40.5 & 12.9 \\
\hline \multirow{3}{*}{$\begin{array}{l}\text { Physical activity Daily } \\
\text { (MET-hours per day) }\end{array}$} & $24-36.5$ & $43,226(33.1)$ & 14.3 & 26.9 & 3.0 \\
\hline & $36.6-44.9$ & $61,532(47.2)$ & 8.3 & 21.8 & 1.8 \\
\hline & $\geq 45$ & $25,673(19.7)$ & 16.8 & 23.4 & 1.9 \\
\hline \multirow[t]{5}{*}{ Economic status } & 1st quintile (the poorest) & $26,159(20.0)$ & 11.7 & 30.0 & 3.1 \\
\hline & 2nd quintile & $26,148(20.0)$ & 12.8 & 27.5 & 2.4 \\
\hline & 3rd quintile & $26,105(20.0)$ & 12.2 & 24.9 & 2.1 \\
\hline & 4th quintile & $26,095(20.0)$ & 12.7 & 23.8 & 1.8 \\
\hline & 5th quintile (the richest) & $26,063(20.0)$ & 10.3 & 17.6 & 1.2 \\
\hline
\end{tabular}




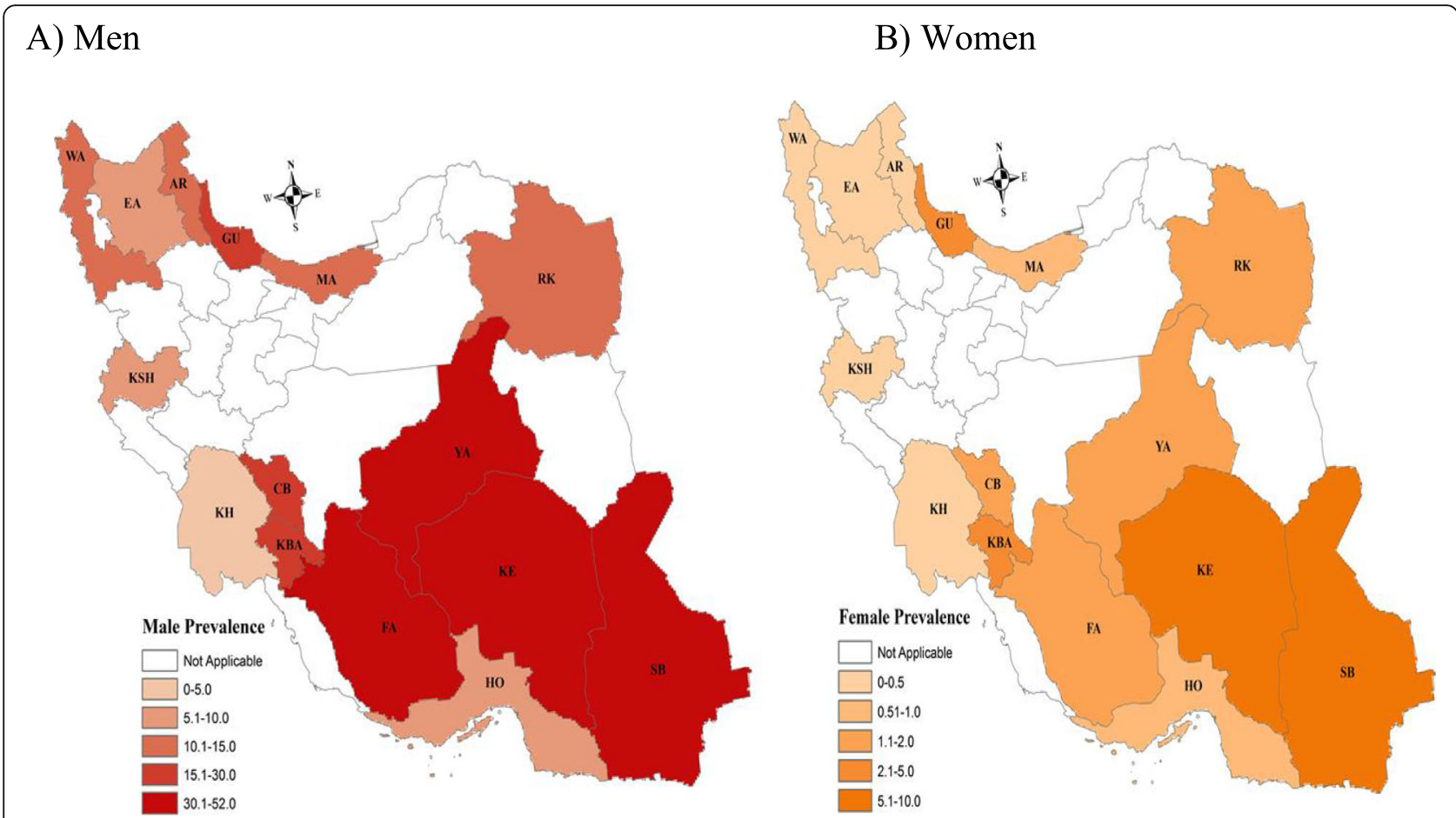

Fig. 1 Prevalence of drug use in men and women across 15 provinces in Iran

and Boyer-Ahmad (KBA), and Chaharmahal and Bakhtiari $(\mathrm{CB})$ provinces. Among women, higher prevalence was found in the provinces of Sistan and Baluchestan $(\mathrm{SB})$, Kerman (KR) and Gilan (GU).

The estimated $C$ was equal to -0.021 , suggesting the higher concentration of drug use among the population with low SES. Moreover, socioeconomic inequality in drug use was found to be higher in women than in men. This is also evident in Fig. 2 where the Concentration curve for drug use for female lies above to the Concentration curve for male. The $45^{\circ}$ line (blue line) is the perfect inequality that is equal to average health status.

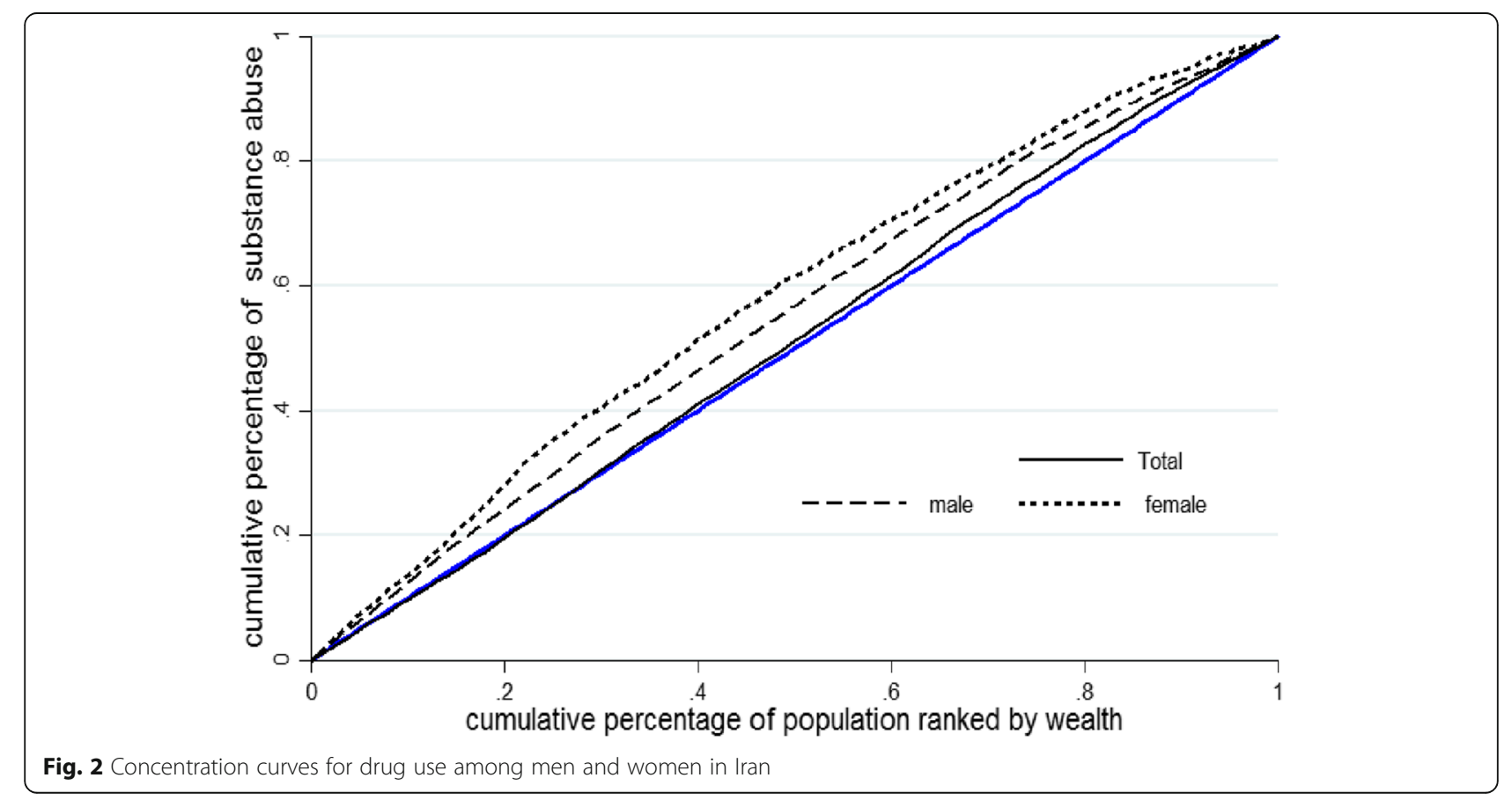


All provinces, except for Khouzestan $(\mathrm{KH})$ and West Azarbaijan (WA), the estimated value of $C_{n}$ showed that druguse is concentrated among low SES groups. The sign of the $C_{n}$ was positive for women in the provinces such as Kermanshah (KSH), Mazandaran (MA), Khouzestan $(\mathrm{KH})$, Hormozgan (HO), West Azerbaijan (WA) and Kohgiluyeh and Boyer-Ahmad (KB). For men, the $C_{n}$ value was positive for Khuzestan $(\mathrm{KH})$ and West Azerbaijan provinces only. The pattern of socioeconomic-related inequality for men in the cohort population was similar to women (see Fig. 3).

\section{Determinants of socioeconomic-related inequalities}

Due to the Simpson paradox [22] on the total value of the $C_{n}$, decomposition analysis was performed for men and women, separately. Simpson paradox or reversal paradox is a phenomenon in probability and statistics, in which a trend appears in several different groups of data but disappears or reverses when these groups are combined. Table 2 presents the results of the decomposition of the $C_{n}$. The results of $C_{k}$ revealed that the prevalence of variables like being single, widowed/divorced, underweight, older ages, smoking and higher levels of physical activity is more concentrated among low SES groups. In contrast, the prevalence of alcohol consumption, obesity and overweight is higher in the high SES groups. The values of $C_{k}$ indicated that higher concentrations of obese and overweight individuals among high-SES.
For women, SES (26.37\%), residence province $(-22.38 \%)$ and age $(9.76 \%)$ had the most significant contribution to socioeconomic inequality in drug use, respectively. For men, SES (80.04\%), smoking (32.04\%) and alcohol consumption $(-12.37 \%)$ were the main contributors to socioeconomic inequality in drug use in Iran.

\section{Discussion}

Our study indicated that $11.9 \%$ (24.1\% among men versus $2.2 \%$ among women) of the adult population in Iran used the illicit drug more than one time in their lifetime. In addition, 14 and $9 \%$ of the participants were a current smoker and had history of alcohol consumption, respectively. These results are in line with the findings of earlier studies investigating the drug use, cigarette smoking and alcohol consumption among Iranian adults. For example, the obtained results of study carried out by Jalilian et al. [15] indicated that 19.4 and $10.1 \%$ of the Iranian adults reported history of cigarette smoking, and alcohol drinking respectively. As well as, Mohebbi et al. [16] carried out a study on 2065 adults aged 18 years and older in Iran and reported that lifetime experience of drug use was $12.9 \%(21.5 \%$ among men versus $4 \%$ among women).

Drug use is a concerning health problem among Iranian population [23]. Moreover, since the alcohol drink and narcotics are illegal in Iran we thought that fear of confrontation with legal authorities may affect our study participation rate [24]. These results can be warning to health policy makers in Iran.

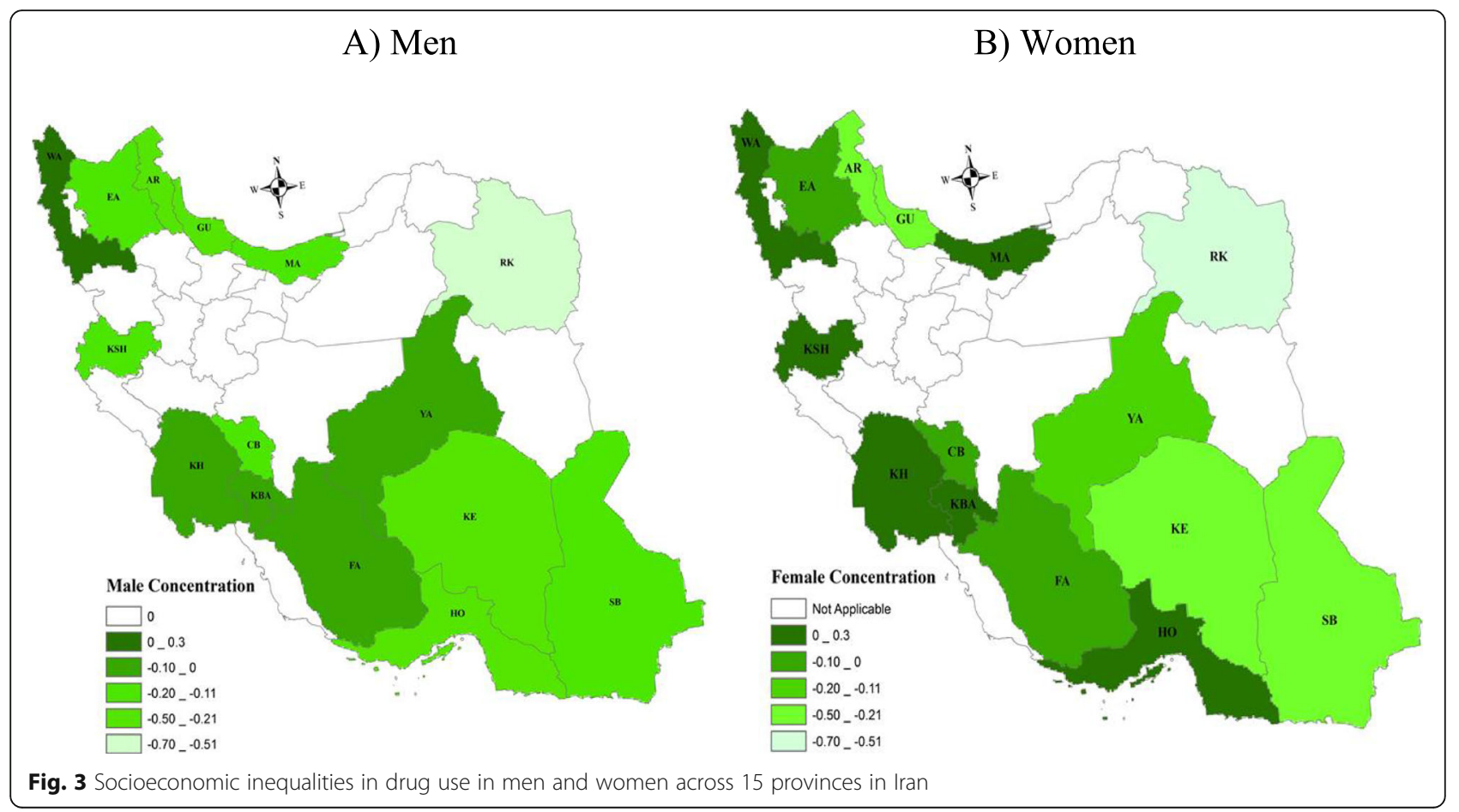




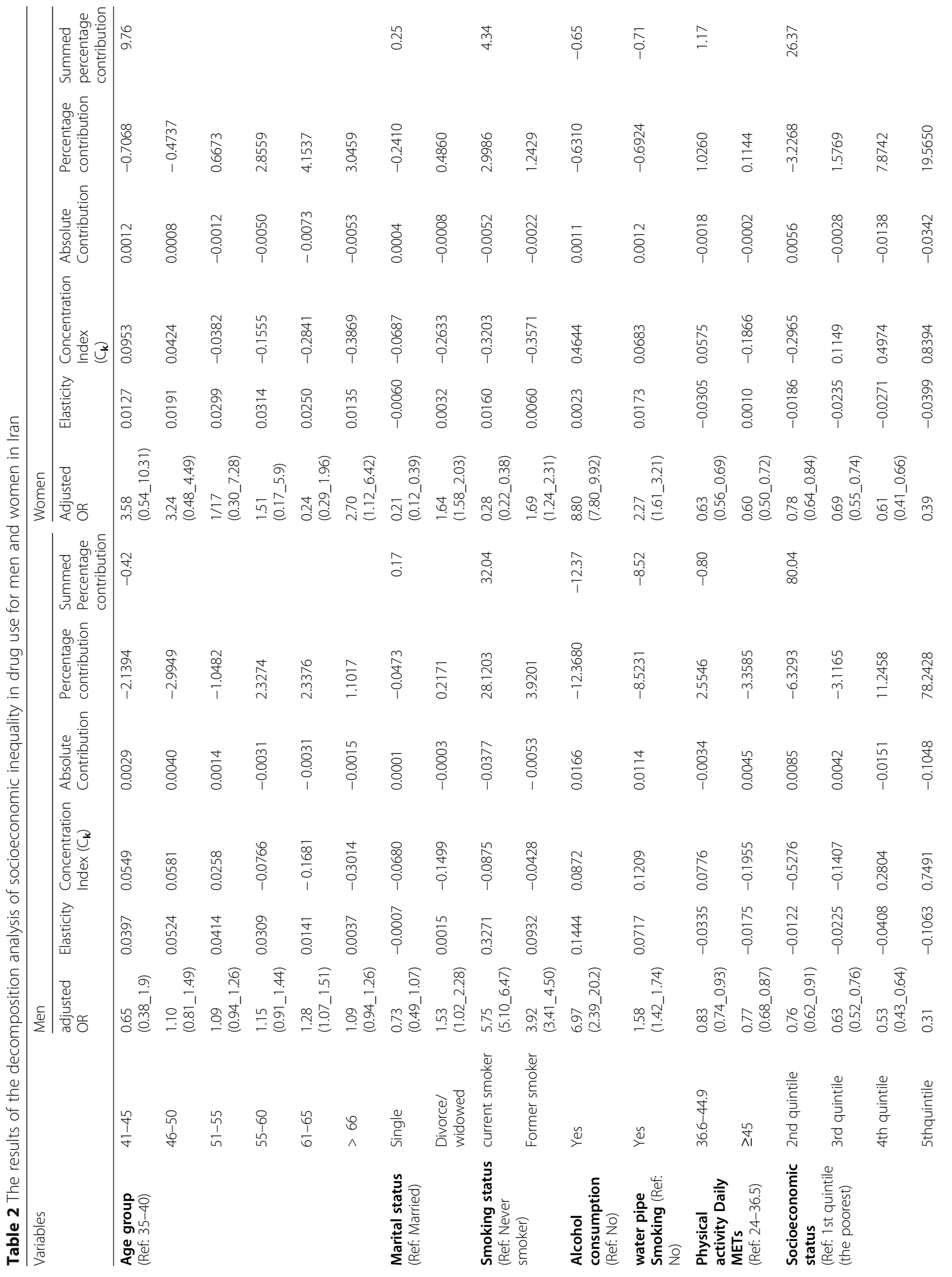




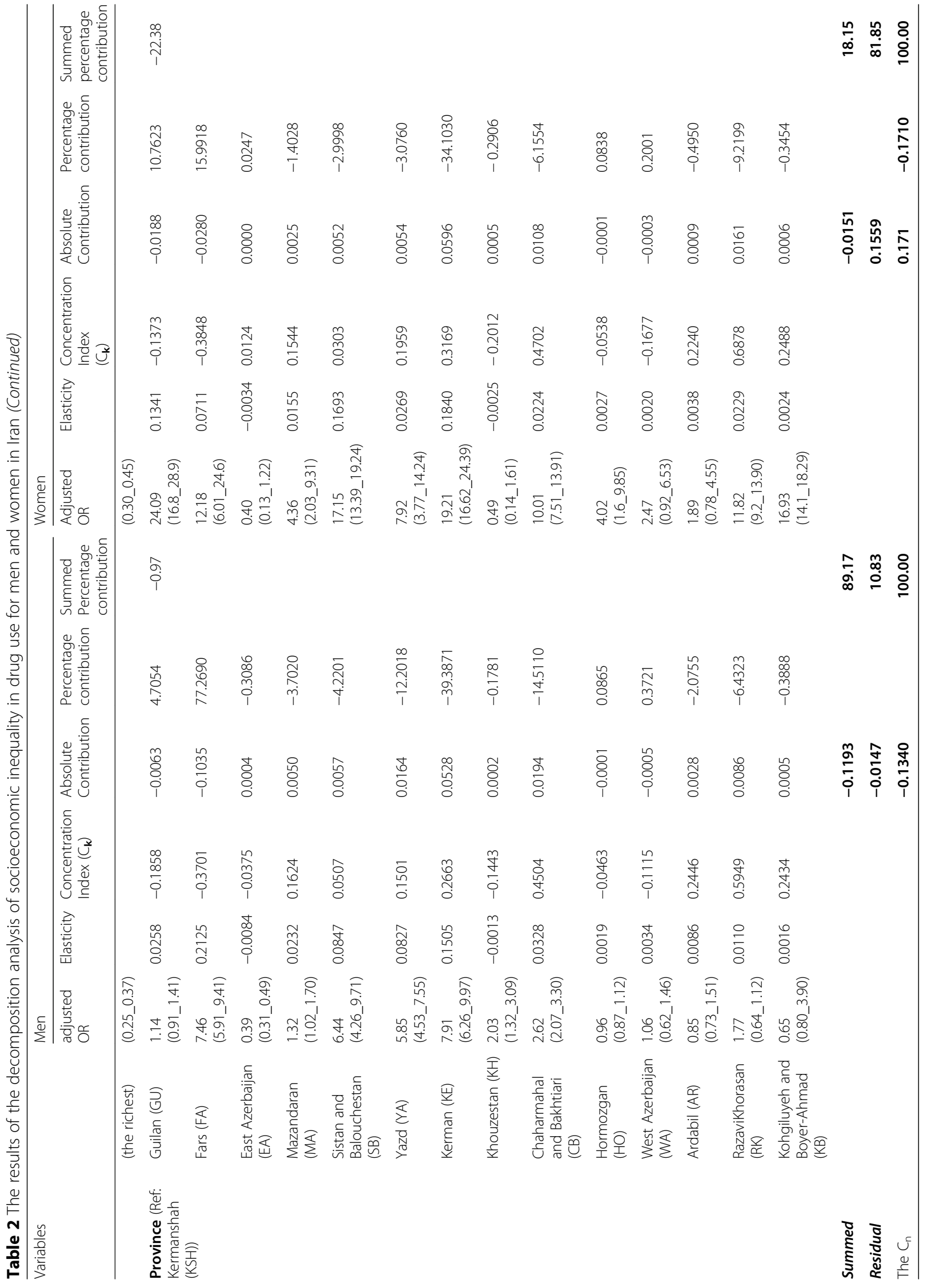


Our findings suggested that drug use is more concentrated among the population with low socioeconomic status in Iran. This result is similar to the results reported by other studies. For example, Lawana and Booysen in their study in South African reported alcohol use is more concentrated among the lower socioeconomic groups [25]. Furthermore, Nikfarjam et al. in their study in total 12,293 samples in Iran reported the relative frequency of alcohol use among males was about 8 times higher than females [26]. Evidence points to the lower socio-economic groups suffer multiple deprivations [27]. For example, studies have been indicated association between lower SES and the following risk factors: cigarettes smoking; drug use problems; psychosocial stress; obesity; lack of social support; and less use of health care services [27-29]. Our study indicated that the drug use is more concentrated among the lower SES groups. Concerted government efforts, within the health sector (for example, pay special attention to groups with lower SES for drug addiction treatment) is required for eliminate inequality.

Furthermore, SES.

For men, SES (80.04\%), smoking (32.04\%) and alcohol consumption $(-12.37 \%)$ were the main contributors to socioeconomic inequality in drug use.

Also, the results of our study indicated that the SES had more contribution to socioeconomic inequality in drug use among men compared to women $(80.04 \%$ VS 26.37\%). Moreover, drug use prevalence was higher among the male population $(24.1 \%$ among men versus $2.2 \%$ among women). This finding is in line with other studies that indicated that men are at higher risk of drug use than women [11, 30, 31]. A study by Do et al also indicated a higher proportion of drug use among men as compared than women in Vietnam [14]. Thus, specific strategies in order to prevention of drug use for this group should be dispensed by policy-makers.

Another finding of current study was indicated the prevalence of drug use was decreased by increased education level. In this regard, Lee et al. in their longitudinal study on 808 male and females elementary school students followed to age 30 indicated earning a high school diploma lessens the risk of drug use problems which contribute to economic instability in young adulthood [28]. Also, in line with our findings Kessler et al. carried out a study on 9282 English speakers 18 years and older in the coterminous United States and reported that lower education was associated with increased comorbid mental health and drug use problems [32]. Several studies have underlined higher education level as a protective factor against drug use [16, 33]. Our findings suggest that the drug use prevention program should focus on less-educated adults in Iran.

Our study also showed that the prevalence of drug use linearly increased by age in women but did not change significantly in men. Moreover, the highest prevalence of drug use was in married group. These findings are somewhat consistent with other studies in Iran. For example, Amin-Esmaeili et al. reported that the odds of drug use related-disorders were higher in previously married as compared to currently married or single adults in Iran [34]. However, Mohebbi et al. demonstrated that divorced or widowed adults reported a higher rate of opium use which is inconsistent with the present study found [16]. It is also inconsistent with our findings, Motevalian et al. in their study indicated that the prevalence of drug use increased in men and women with an increase in age [35].

Because of proximity to Afghanistan (the country with the greatest opium production in the world) Iran seems to have the conditions for being a significant place for drug use [4]. As our findings show, drug use was more prevalent in neighboring provinces with Afghanistan.

\section{Study limitations}

Although our study has several strengths including large sample size, the results reported in this study should be interpreted in light of some limitations. First, our study is cross-sectional nature; thus, no causal inference can be derived from the associations reported in the paper. Second, self-reporting information may be subject to recall bias. Third, since the inclusion age of our study was 35 years and older, it may affect one affect the results and the estimated lifetime prevalence and type of drug use. Finally, the our study investigated drug use and alcohol consumption history more than one time during lifetime using yes-no scale, which was the main limitations of the current study and asks for more attention.

\section{Conclusions}

There are multiple factors to explain the drug use inequality among Iranian people. The present study confirmed the applicability of the SES to explain drug use among Iranian population. We found that higher rate of drug use among low-SES. Thus, drug use prevention programs in Iran should target low SES adults in order to reduce inequalities in drug use in Iran. Our finding could be useful for health policy maker to design and implement effective preventative programs to protect Iranian population against the drug use. 


\section{Appendix}

Table $\mathbf{3}$ The cohort population in the study provinces

\begin{tabular}{|c|c|c|c|c|c|c|}
\hline Row & Province & *Population & Cohort site & *Population & Cohort population & Main Ethnicities \\
\hline 1 & Ardabil & $1,270,420$ & Ardabil & 529,374 & 8192 & Azeri (Turk) \\
\hline 2 & Chaharmahal and Bakhtiari & 947,763 & Sharekord & 93,104 & 6664 & Lur \\
\hline 3 & East Azerbaijan & $3,909,652$ & Khameneh & 3056 & 14,978 & Azeri (Turk) \\
\hline \multirow[t]{3}{*}{4} & \multirow[t]{3}{*}{ Fars } & \multirow[t]{3}{*}{$4,851,274$} & Kavar & 31,711 & 2244 & Fars (Persian), Turk \\
\hline & & & Kharameh & 18,477 & 10,662 & Fars (Persian), Arab \\
\hline & & & Fasa & 110,825 & 10,113 & Fars (Persian), Arab and Turk \\
\hline 5 & Guilan & $2,530,696$ & Some'e Sara & 58,658 & 10,512 & Gilaki \\
\hline 6 & Hormozgan & $1,776,415$ & Bandare Kong & 19,213 & 3570 & Arab \\
\hline 7 & Kerman & $3,164,718$ & Rafsanjan & 161,909 & 9982 & Fars (Persian) \\
\hline 8 & Kermanshah & $1,952,434$ & Ravansar & 47,657 & 10,077 & Kurd \\
\hline 9 & Khouzestan & $4,710,506$ & Hoveizeh & 19,481 & 9156 & Arab \\
\hline 10 & Mazandaran & $3,283,582$ & Sari & 309,820 & 10,253 & Tabari \\
\hline \multirow[t]{2}{*}{11} & \multirow[t]{2}{*}{ RazaviKhorasan } & \multirow[t]{2}{*}{$6,434,501$} & Mashhad & $3,001,184$ & 2189 & Fars (Persian) \\
\hline & & & Sabzevar & 243,700 & 784 & Fars (Persian) \\
\hline 12 & Sistan and Balouchestan & $2,775,014$ & Zahedan & 587,730 & 8318 & Balouch \\
\hline 13 & West Azerbaijan & $3,265,219$ & Ghoushchi & 2787 & 3662 & Azeri (Turk) \\
\hline 14 & Yazd & $1,138,533$ & Shahedieh, Yazd & 18,309 & 9901 & Fars (Persian) \\
\hline 15 & Kohgiluyeh and Boyer-Ahmad & $7,313,052$ & Dena & 52,242 & 421 & Lur \\
\hline
\end{tabular}

*The frequency of population is according to Iranian Population and Housing Census in 2016

\section{Abbreviations}

C: Concentration Index; KUMS: Kermanshah University of Medical Science; MoHME: Ministry of Health and Medical Education; NHIS: National Health Interview Survey; NCDs: Non-communicable Diseases; OR: Odds Ratios; PCA: Principal Component Analysis; PERSIAN: Prospective Epidemiologic Research Study in Iran; SES: Socioeconomic Status; WHO: World Health Organization

\section{Acknowledgments}

This research project supported by The Iranian Ministry of Health and Medical Education has contributed to the funding used in The PERSIAN Cohort through Grant no. 700/534. We would like to thank deputy of research of Iranian Ministry of Health and Medical Education and Kermanshah University of Medical Sciences for financial support.

\section{Consent to publication}

Not applicable.

\section{Authors' contributions}

Study concept and design, Farid Najafi, Yahya Pasdar, Behrooz Hamzeh, Ali Akbar Haghdoost, Reza Malekzadeh, and Hossein Poustchi. Analysis and interpretation of data, Mehdi Moradinazar, Farzad Jalilian, Mehdi MirzaeiAlavijeh, Mahin Amini, and Ali Mohammadi. Drafting of the manuscript, Marzeyeh Nasiri, Ebraim Shakiba, Hassan Okati-Aliabad, Majid Saeedi, Fariborz Mansour-Ghanaei, Sara Farhang, Ali Reza Safarpour, Najmeh Maharlouei, Mojtaba Farjam, and Saeed Amini. Critical revision of the manuscript for important intellectual content, Farzad Jalilian, Mohammad Hajizadeh and Mehdi MirzaeiAlavijeh; All authors provided comments and approved the final manuscript.

\section{Funding}

This work funded by Iran's Ministry of Health and Medical Education (MoHME) and Kermanshah University of Medical Sciences (KUMS).
Availability of data and materials

Data used for this study can be accessed upon request from the first author (Dr. Moradinazar) at m.moradinazar@gmail.com

Ethics approval and consent to participate

While each cohort center received the ethical approval from local universities, for the purpose of this study and pooling all PERSIAN data, the ethics committee of Kermanshah University of Medical Sciences approved the study (IR.KUMS.REC.1397.187).

\section{Competing interests}

The authors declare no conflict of interest.

\section{Author details}

${ }^{1}$ Research Center for Environmental Determinants of Health (RCEDH), Health Institute, Kermanshah University of Medical Sciences, Kermanshah, Iran. ${ }^{2}$ Social Development and Health Promotion Research Center, Health Institute, Kermanshah University of Medical Sciences, Kermanshah, Iran. ${ }^{3}$ School of Health Administration, Faculty of Health, Dalhousie University, Halifax, Canada. ${ }^{4}$ Modeling in Health Research Center, Institute for Future Studies in Health, Kerman University of Medical Sciences, Kerman, Iran. ${ }^{5}$ Digestive Diseases Research Center, Digestive Diseases Research Institute, Tehran University of Medical Sciences, Tehran, Iran. ${ }^{6}$ Digestive Oncology Research Center, Digestive Diseases Research Institute, Tehran University of Medical Sciences, Tehran, Iran. ${ }^{7}$ Modelling in health Research Center, Shahrekord University of Medical Sciences, Shahrekord, Iran. ${ }^{8}$ Health Promotion Research Center, Zahedan University of Medical Sciences, Zahedan, Iran. ${ }^{9}$ Department of Pharmaceutics, School of Pharmacy, Mazandaran University of Medical Sciences, Sari, Iran. ${ }^{10}$ Gastrointestinal and Liver Diseases Research Center, Guilan University of Medical Sciences, Rasht, Iran. " Medical sciences, Tabriz, Iran. ${ }^{12}$ Gastroenterohe Pathology Research Center, Shiraz University of Medical Sciences, Shiraz, Iran. ${ }^{13}$ Health Policy Research Center, Shiraz University of Medical Sciences, Shiraz, Iran.

${ }^{14}$ Non-communicable diseases Research Center, Fasa University of Medical 
Sciences, Fasa, Iran. ${ }^{15}$ Health Services Management, Arak University of Medical Sciences, Arak, Iran.

\section{Received: 26 October 2019 Accepted: 28 May 2020}

Published online: 05 June 2020

\section{References}

1. Ahmadpanah M, Mirzaei-Alavijeh M, Allahverdipour H, Jalilian F, Haghighi M, Afsar $A$, et al. Effectiveness of coping skills education program to reduce craving beliefs among addicts referred to addiction centers in Hamadan: a randomized controlled trial. Iran J Public Health. 2013:42(10):1139.

2. Compton WM, Boyle M, Wargo E. Prescription opioid abuse: problems and responses. Prev Med. 2015:80:5-9.

3. Lal R, Deb KS, Kedia S. Substance use in women: current status and future directions. Indian J Psychiatry. 2015:57(Suppl 2):S275.

4. Amirabadizadeh A, Nezami H, Vaughn MG, Nakhaee S, Mehrpour O. Identifying risk factors for drug use in an Iranian treatment sample: a prediction approach using decision trees. Substance use \& misuse. 2018; 53(6):1030-40.

5. Soroosh D, Neamatshahi M, Zarmehri B, Nakhaee S, Mehrpour O. Druginduced prolonged corrected QT interval in patients with methadone and opium overdose. Subst Abuse Treat Prev Pol. 2019;14(1):8.

6. Eskandarieh S, Jafari F, Yazdani S, Hazrati N, Saberi-Zafarghandi MB. Compulsory maintenance treatment program amongst Iranian injection drug users and its side effects. Int J High Risk Behav Addiction. 2014;3(4): e21765.

7. Kok G, Gottlieb NH, Peters GJ, Mullen PD, Parcel GS, Ruiter RA, et al. A taxonomy of behaviour change methods: an intervention mapping approach. Health Psychol Rev. 2016;10(3):297-312.

8. Gullo MJ, Matveeva M, Feeney GF, Young RM, Connor JP. Social cognitive predictors of treatment outcome in cannabis dependence. Drug Alcohol Depend. 2017;170:74-81

9. Otten R, Mun CJ, Dishion TJ. The social exigencies of the gateway progression to the use of illicit drugs from adolescence into adulthood. Addict Behav. 2017:73:144-50.

10. Almeida-Filho N, Lessa I, Magalhães L, Araújo MJ, Aquino E, James SA, et al. Social inequality and alcohol consumption-abuse in Bahia, Brazil. Soc Psychiatry Psychiatr Epidemiol. 2005;40(3):214-22.

11. Do HN, Nathan N, Van Nguyen B, Le HT, Nguyen HQ, Nguyen AT, et al. Sociodemographic inequalities in substance use among young people in Vietnam. Child Youth Serv Rev. 2018;94:644-9.

12. Hiscock R, Bauld L, Amos A, Fidler JA, Munafò M. Socioeconomic status and smoking: a review. Ann N Y Acad Sci. 2012;1248(1):107-23.

13. Patrick ME, Wightman P, Schoeni RF, Schulenberg JE. Socioeconomic status and substance use among young adults: a comparison across constructs and drugs. J Stud Alcohol Drugs. 2012;73(5):772-82.

14. Redonnet B, Chollet A, Fombonne E, Bowes L, Melchior M. Tobacco, alcohol, cannabis and other illegal drug use among young adults: the socioeconomic context. Drug Alcohol Depend. 2012;121(3):231-9.

15. Jalilian F, KaramiMatin B, Ahmadpanah M, Ataee M, AhmadiJouybari T, Eslami AA, et al. Socio-demographic characteristics associated with cigarettes smoking, drug abuse and alcohol drinking among male medical university students in Iran. J Res Health Sci. 2015;15(1):42-6.

16. Mohebbi E, Haghdoost AA, Noroozi A, Vardanjani HM, Hajebi A, Nikbakht R, et al. Awareness and attitude towards opioid and stimulant use and lifetime prevalence of the drugs: a study in 5 large cities of Iran. Int J Health Policy Manag. 2019;8(4):222.

17. Rostami M, Karamouzian M, Khosravi A, Rezaeian S. Gender and geographical inequalities in fatal drug overdose in Iran: A provincelevel study in 2006 and 2011. Spatial Spatio-Temporal Epidemiology. 2018:25:19-24.

18. Poustchi H, Eghtesad S, Kamangar F, Etemadi A, Keshtkar AA, Hekmatdoost A, et al. Prospective epidemiological research studies in Iran (the PERSIAN cohort study): rationale, objectives, and design. Am J Epidemiol. 2017;187(4): 647-55

19. Eghtesad S, Mohammadi Z, Shayanrad A, Faramarzi E, Joukar F, Hamzeh B, et al. The PERSIAN cohort: providing the evidence needed for healthcare reform. Arch Iran Med. 2017;20(11):691.

20. Ryan H, Trosclair A, Gfroerer J. Adult current smoking: differences in definitions and prevalence estimates-NHIS and NSDUH, 2008. J Environ Public Health. 2012;2012:918368 11 pages.
21. Wagstaff A, Paci P, Van Doorslaer E. On the measurement of inequalities in health. Soc Sci Med. 1991:33(5):545-57.

22. Fiedler K, Walther E, Freytag P, Nickel S. Inductive reasoning and judgment interference: experiments on Simpson's paradox. Personal Soc Psychol Bull. 2003;29(1):14-27.

23. Sharifi H, Shokoohi M, Ahmad RafieiRad A, SargolzaieMoghadam M, Haghdoost AA, Mirzazadeh A, Karamouzian M. Methamphetamine use among Iranian youth: a population-based knowledge, attitude, and practice study. Subst Use Misuse. 2017:52(9):1214-21.

24. Allahverdipour $H$, Jalilian F, Shaghaghi A. Vulnerability and the intention to anabolic steroids use among Iranian gym users: an application of the theory of planned behavior. Subst Use Misuse. 2012;47(3):309-17.

25. Lawana N, Booysen F. Decomposing socioeconomic inequalities in alcohol use by men living in south African urban informal settlements. BMC Public Health. 2018;18(1):993.

26. Nikfarjam A, Hajimaghsoudi S, Rastegari A, Haghdoost AA, Nasehi AA, Memaryan $\mathrm{N}$, et al. The frequency of alcohol use in Iranian urban population: the results of a national network scale up survey. Int J Health Policy Manag. 2017;6(2):97.

27. Ataguba JE, Akazili J, Mclntyre D. Socioeconomic-related health inequality in South Africa: evidence from general household surveys. Int J Equity Health. 2011;10(1):48.

28. Lee JO, Herrenkohl TI, Kosterman R, Small CM, Hawkins JD. Educational inequalities in the co-occurrence of mental health and substance use problems, and its adult socio-economic consequences: a longitudinal study of young adults in a community sample. Public Health. 2013:127(8):745-53.

29. Mackenbach JP. Socio-economic health differences in the Netherlands: a review of recent empirical findings. Soc Sci Med. 1992;34(3):213-26.

30. Hicks BM, Blonigen DM, Kramer MD, Krueger RF, Patrick CJ, lacono WG, et al. Gender differences and developmental change in externalizing disorders from late adolescence to early adulthood: a longitudinal twin study. J Abnorm Psychol. 2007;116(3):433.

31. King KM, Chassin L. A prospective study of the effects of age of initiation of alcohol and drug use on young adult substance dependence. J Stud Alcohol Drugs. 2007:68(2):256-65.

32. Kessler RC, Chiu WT, Demler O, Walters EE. Prevalence, severity, and comorbidity of 12-month DSM-IV disorders in the National Comorbidity Survey Replication. Arch Gen Psychiatry. 2005;62(6):617-27.

33. Drope J, Liber AC, Cahn Z, Stoklosa M, Kennedy R, Douglas CE, Henson R, Drope J. Who's still smoking? Disparities in adult cigarette smoking prevalence in the United States. CA Cancer J Clin. 2018;68(2):106-15.

34. Amin-Esmaeili M, Rahimi-Movaghar A, Sharifi V, Hajebi A, Radgoodarzi R, Mojtabai R, et al. Epidemiology of illicit drug use disorders in Iran: prevalence, correlates, comorbidity and service utilization results from the Iranian mental health survey. Addiction. 2016;111(10):1836-47.

35. Motevalian A, Sahebi R, RahimiMovaghar A, Yunesian M. Age, period, and cohort effects on alcohol and drug use among students of Tehran university of medical sciences from 2006 to 2009. Iran J Epidemiol. 2015 Sep 15;11(2):99-108

\section{Publisher's Note}

Springer Nature remains neutral with regard to jurisdictional claims in published maps and institutional affiliations.

Ready to submit your research? Choose BMC and benefit from

- fast, convenient online submission

- thorough peer review by experienced researchers in your field

- rapid publication on acceptance

- support for research data, including large and complex data types

- gold Open Access which fosters wider collaboration and increased citations

- maximum visibility for your research: over $100 \mathrm{M}$ website views per year

At BMC, research is always in progress.

Learn more biomedcentral.com/submissions 